\title{
Seljuk Ewers and trays an archaeological artistic study
}

\author{
Prof. Dr. Atef Saad Mohamed Mahmoud \\ Professor, Faculty of Archaeology South Valley University at Qina, Egypt \\ Dr. Hagag Ahmed Sayed Ahmed \\ Lecturer, Faculty of Archaeology South Valley University at Qina, Egypt
}

\begin{abstract}
:
This study deals with a range of metal ewers and trays, published for the first time, with never before published, made of copper or bronze inlaid with silver, all due to the Seljuk era through the centuries VI - VII / AD XII - XIII centuries.

The study is an attempt to shed light on the type of metal pans in the era of Seljuk, characterized by mature and rich artwork, especially in the metal working industry which has received a series of studies, in that era in particular, whether in eastern Iran and Khorasan specifically or in Iraq, and Mosul in particular, which was characterized by techniques in the industry and forming and decoration, as we shall see, One of the reasons that led me to this study next to the dissemination of antiques for the first time, the lack of scientific study specialist dealing with the kind of ewers - despite the many studies that have found metal objects Seljuk - with the exception of some studies minor has published some them in the folds of talk about antiques and other metal, without appropriation or limitation, which made me look at the inside of Special Collections, as well as the work of Orientalist scholars to compare.
\end{abstract}

